\section{BMJ Global Health}

\title{
"Most of what they do, we cannot do!" How lay health workers respond to barriers to uptake and retention in HIV care among pregnant and breastfeeding mothers in Malawi
}

\author{
Stephanie M Topp (D) , ${ }^{1}$ Nicole B Carbone,${ }^{2}$ Jennifer Tseka, ${ }^{2}$ Linda Kamtsendero, ${ }^{2}$ \\ Godfrey Banda, ${ }^{2}$ Michael E Herce ${ }^{3,4}$
}

\begin{abstract}
To cite: Topp SM, Carbone NB, Tseka J, et al. "Most of what they do, we cannot do!" How lay health workers respond to barriers to uptake and retention in HIV care among pregnant and breastfeeding mothers in Malawi. BMJ Global Health 2020;5:e002220. doi:10.1136/ bmjgh-2019-002220
\end{abstract}

Handling editor Seye Abimbola

Received 10 December 2019 Revised 6 May 2020 Accepted 9 May 2020

Check for updates

\section{(C) Author(s) (or their} employer(s)) 2020. Re-use permitted under CC BY-NC. No commercial re-use. See rights and permissions. Published by BMJ.

${ }^{1}$ College of Public Health, Medical and Veterinary Sciences, James Cook University, Townsville, Queensland, Australia ${ }^{2}$ University of North Carolina Project, Lilongwe, Malawi ${ }^{3}$ Division of Infectious Diseases, University of North Carolina School of Medicine, Chapel HIII, North Carolina, USA ${ }^{4}$ Implementation Science Unit, Centre for Infectious Disease Research in Zambia (CIDRZ), Lusaka, Zambia

Correspondence to Dr Stephanie M Topp; globalstopp@gmail.com

\section{ABSTRACT}

Background In the era of Option B+ and 'treat all' policies for HIV, challenges to retention in care are well documented. In Malawi, several large community-facility linkage (CFL) models have emerged to address these challenges, training lay health workers (LHW) to support the national prevention of mother-to-child transmission (PMTCT) programme. This qualitative study sought to examine how PMTCT LHW deployed by Malawi's three most prevalent CFL models respond to known barriers to access and retention to antiretroviral therapy (ART) and PMTCT.

Methods We conducted a qualitative study, including 43 semi-structured interviews with PMTCT clients; 30 focus group discussions with Ministry of Health ( $\mathrm{MOH}$ )-employed lay and professional providers and PMTCT LHWs; a facility CFL survey and $2-4$ hours of onsite observation at each of 8 sites and in-depth interviews with 13 programme coordinators and $\mathrm{MOH}$ officials. Thematic analysis was used, combining inductive and deductive approaches. Results Across all three models, PMTCT LHWs carried out a number of 'targeted' activities that respond directly to a range of known barriers to ART uptake and retention. These include: (i) fulfilling counselling and educational functions that responded to women's fears and uncertainties; (ii) enhancing women's social connectedness and participation in their own care and (iii) strengthening service function by helping clinicbased providers carry out duties more efficiently and effectively. Beyond absorbing workload or improving efficiency, however, PMTCT LHWs supported uptake and retention through foundational but often intangible work to strengthen CFL, including via efforts to strengthen facilityside responsiveness, and build community members' recognition of and trust in services.

Conclusion PMTCT LHWs in each of the CFL models examined, addressed social, cultural and health system factors influencing client access to, and engagement with, HIV care and treatment. Findings underscore the importance of person-centred design in the 'treatall' era and the contribution LHWs can make to this, but foreground the challenges of achieving personcentredness in the context of an under-resourced health system. Further work to understand the governance and

\section{Key questions}

What is already known?

- In the era of treat-all policies for prevention of mother-to-child transmission of HIV (PMTCT) and antiretroviral therapy (ART), uptake but particularly long-term engagement in care are ongoing challenges.

- Current strategies for strengthening retention and engagement along the PMTCT service 'cascade' include community-facility linkage models that deploy lay health workers (LHWs) to support various aspects of service delivery in clinic and community settings.

- Malawi's PMTCT programme is currently heavily supported by LHWs recruited under three nongovernment funded community-facility linkage models-Mentor Mothers, Expert Clients and Tingathe-Community Health Workers.

sustainability of these project-funded CFL models and LHW cadres is now urgently required.

\section{INTRODUCTION}

In 2012, WHO published recommendations for the adoption of lifelong combination antiretroviral therapy (ART) for all pregnant and breastfeeding women living with HIV, regardless of their $\mathrm{CD} 4+$ cell count or clinical staging. ${ }^{1}$ Coined Option B+ after initial implementation in Malawi, the recommendations represented an evolution from earlier WHO guidelines (that employed clinical algorithms for ART eligibility) and adopted a public health approach to ensure all pregnant and breastfeeding women living with HIV had access to lifelong ART immediately following HIV diagnosis. The dual aims were to save 


\section{Key questions}

\section{What are the new findings?}

- Across all three models, PMTCT LHWs carried out many 'targeted' activities that responded directly to a range of known barriers to ART uptake and retention-these included: (i) carrying out critical counselling and educational functions that addressed prevalent fears about treatment; (ii) enhancing social connectedness and patient participation in their own care; (iii) strengthening facilities capacity to deliver services effectively and efficiently.

- PMTCT LHWs also supported uptake and retention through foundational but often intangible work to strengthen community-facility linkage, including via efforts to strengthen facility-side patient centredness and responsiveness, and build community members' recognition of and trust in services.

\section{How do the new findings imply?}

- Findings underscore the importance of person-centred design in the 'treat-all' era and the contribution LHWs can make to this, but also foreground the challenges of achieving such in the context of an under-resourced health system.

- Understanding in what ways PMTCT LHWs are supporting efforts to address known barriers to uptake and long-term engagement in ART - in both targeted and more systemic ways-should help inform decisions about strategic investments in both PMTCT and ART programming and core health system functions such as human resource capacity.

maternal lives and to ensure prevention of mother-tochild transmission of HIV (PMTCT). ${ }^{12}$ Malawi was the first country in the world to introduce Option $\mathrm{B}+$ with policy adoption driven by a combination of factors, ${ }^{34}$ including desire to maximise ART coverage and eliminate paediatric HIV and the need to simplify clinical programming and better integrate ART and PMTCT guidelines in an under-resourced health system. ${ }^{4}$

Implementation of Option $\mathrm{B}+$ produced impressive early results in Malawi. In the first quarter of Option B+ implementation alone, Malawi reported a $748 \%$ increase in the number of pregnant women living with HIV who started lifelong treatment. ${ }^{3}$ Yet impressive programmatic and health gains were accompanied by a number of challenges. In 2014, Tenthani et al found that Malawian women who started ART via Option $\mathrm{B}+$ were five times more likely to never return to care after their initial visit, and twice as likely to miss their first follow-up visit, compared with women who started ART through other channels, including self-referral via voluntary testing and counselling. ${ }^{5}$ In 2015, Kim et al reported that although Option B+ dramatically improved rates of ART initiation, loss to follow-up of Malawian women living with HIV following the birth of their child increased from 5.8\% before Option $\mathrm{B}+$ to $11.2 \%$ after Option $\mathrm{B}+$ was introduced. ${ }^{6}$ The most recent Malawi national data showed that $26 \%$ of Malawian pregnant women became lost to follow-up within 12 months of starting treatment. ${ }^{7}$

Reflecting what is now a central challenge of optout test-and-treat models of HIV care in many settings, suboptimal retention among women initiated on ART in
PMTCT has been documented elsewhere in the region. A meta-analysis of sub-Saharan African PMTCT programmes demonstrates retention rates among those initiating care via Option $\mathrm{B}+$ to be below those of the general adult population. ${ }^{8}$ Results from pragmatic universal test-andtreat trials from high HIV-burden countries too, suggest that the issues with linkage to care and early care retention first observed with Option B+ may be not unique to PMTCT and that in the 'treat all' era we will likely require interventions to improve patient engagement along the entire HIV care continuum. ${ }^{9-12}$ Such interventions may need to be differentiated based on the specific population and treatment setting of concern.

Barriers to uptake and long-term engagement in care for pregnant and breastfeeding women have been identified in a number of studies in sub-Saharan Africa, including some specific to women accessing ART via optout Option B+ services. ${ }^{13-15}$ The literature points to the role of women's knowledge of their HIV status, understanding of PMTCT services, disclosure status and male partner support as common factors affecting willingness and ability to start or remain in care. In relation to Option B+ specifically, McLean $e t$ al in a study of women from four countries, demonstrated how feeling 'ready' was central to pregnant women's willingness to start treatment on the same-day, with degree of 'readiness' influenced by their previous knowledge of HIV status, interactions with health workers and their partners and a desire and sense of responsibility to protect their infants. ${ }^{16}$ A rapidly evolving 'engagement in care' literature now documents how the interplay between social and relational factors, individual biological and psychological features and health system design and responsiveness all influence uptake and engagement outcomes. ${ }^{17}$

Various interventions have been developed to address PMTCT and ART retention challenges variously focused on clinic, community or both settings. ${ }^{18}$ Recently, so-called 'differentiated care' models, trialling services not reliant on individual, clinic-based attendance, have shown some promising results. These include ART adherence clubs in Western Province South Africa, ${ }^{19}$ community adherence groups in Tete, Mozambique ${ }^{20}$ and the medication adherence clubs in Nairobi, Kenya. ${ }^{21}$ Long standing earlier versions of 'differentiated care' for HIV services include task-shifting and communityfacility linkage (CFL) using lay health workers (LHWs) in support of more traditional clinic-based services. ${ }^{22-26}$ A feature of both PMTCT and adult ART programmes in Malawi among other sub-Saharan African countries, ${ }^{27} 28$ these CFL approaches ${ }^{29}$ train LHWs to support education, counselling and outreach services across both clinic and community settings.

In Malawi, CFL models using PMTCT LHWs are widespread. ${ }^{3031}$ At the time of this study (2017-19), three such models-Expert Clients, Mentor Mothers and TingatheCommunity Health Workers (hereafter Tingathe-CHW)resourced and overseen by non-government partners, were providing support to Malawi's PMTCT programme 
across much of the country. Although anecdotally well accepted, little has been written about how the PMTCT LHWs mobilised under these models address Malawi's PMTCT and ART engagement challenges. Nested within a larger evaluative effort, this qualitative study set out to improve understanding of (i) what Mentor Mothers, Expert Clients and Tingathe-CHWs (hereafter collectively PMTCT LHWs) do and (ii) how they address barriers to uptake and retention in the Malawian context.

\section{METHODS}

We conducted an exploratory qualitative study seeking to understand, from the perspective of multiple stakeholders, how PMTCT LHWs are responding to barriers to uptake and retention in Malawi's PMTCT and ART programmes. Qualitative research was deemed an appropriate approach as it helps to develop concepts that support stronger understanding of social phenomena in situ, and carries an emphasis on meaning, experience and the views of participants. ${ }^{32}$ Our approach was enabled through collection of observational data as well as in-depth interviews (IDIs) and focus groups that used open-ended questions. Explorations of participants' responses used probes such as 'why', 'how' and 'what' to gain deeper understanding of participants' views and experiences of PMTCT LHWs and their activities. As a reference to local barriers to uptake and retention in ART in Malawi, we were guided by McLean's adaptation of Skovdal's ecological framework for engagement barriers, and their empirically derived framework of factors relating to pregnant women's 'readiness' to start ART.

\section{Study design \& data collection}

Using qualitative methods, we conducted eight ${ }^{8}$ in-depth 'site assessments' to enable detailed exploration of different actors' experiences with PMTCT LHWs and their role in addressing barriers to uptake and retention in PMTCT and ART in 'paired' community and clinic settings. We also conducted seven ${ }^{7}$ rapid site assessments to improve the robustness of the conclusions drawn about PMTCT LHW activities and their health service interface by broadening our observational data of day-to-day clinic and communities activities at additional sites. Site selection was purposive and designed to ensure a demographic mix of clinics and their surrounding catchment areas taking into account the major geographic regions (Northern, Central, Southern) and health zones of Malawi (Northern, Central Eastern, Central Western and South Eastern), the urban versus rural location, size and capacity (eg, hospital vs primary health centre) and the active presence of a PMTCT LHWs (table 1).

Data collection took place between January 2018 and April 2019. At all sites (in-depth and rapid assessment), we completed a closed-ended LHW Facility Survey to characterise activities conducted by LHWs under each of the models, and structured non-participant observations to observe the flow and dynamics of service delivery activities in facilities and the surrounding communities. For in-depth site assessments only, we also: (1) conducted focus group discussions with the different types of PMTCT LHWs, Ministry of Health (MOH) professional health workers (ie, doctors, clinical officers, midwives and nurses), MOH LHWs (eg, Health Surveillance Assistants (HSAs) and clerks); (2) semi-structured interviews with a convenience sample of HIV-positive mothers; (3) conducted IDIs within each major region with key stakeholders such as members of MOH District Health Management Teams and PMTCT LHW managers and supervisors. A team of trained and experienced Malawian research assistants fluent in local languages carried out all data collection activities. The research manager lead daily debriefings, and the lead investigator debriefed with the team approximately every fortnight. Table 1 summarises data collection activities and participants across the sites.

\section{Patient and public involvement}

Due to educational and capacity constraints in the study setting, this research was done without direct patient involvement in study design or dissemination. However, input on study design and implementation was obtained from a multidisciplinary Study Advisory Committee which included Malawian policy makers, health systems experts and service providers, and study findings were disseminated widely among these stakeholders.

Throughout the study, attention was paid to ensuring participants' anonymity. Each participant was given an ID number based on their type (client, provider, manager), and their demographic information, with a link log held on a secure file in a separate location. If participants identified themselves or others in the course of their interview, this was transcribed to aid cross-referencing during analysis, but redacted for purpose of any quotation in reports, presentations or manuscripts. To further reduce the risk of identification, quotations of frontline providers were linked to anonymised site numbers only (eg, site 1, 2, etc) and quotations of more senior participants (eg, district or NGO managers) identified by role only.

\section{Analysis}

Thematic analysis was conducted. To identify major and minor themes, we took the following steps: (a) familiarisation through careful and repeat reading of transcripts and research memos, noting emergent themes; (b) performing open coding in which codes were created based on identified themes, codes were assigned to specific sections of transcripts, with double-coding conducted on a sample of data to promote intercoder reliability; (c) developing a codebook; (d) performing data reduction in which inventory was taken in relation to each given code, capturing the variation or richness of each theme and noting differences between individuals or among subgroups; (e) data display using matrices 


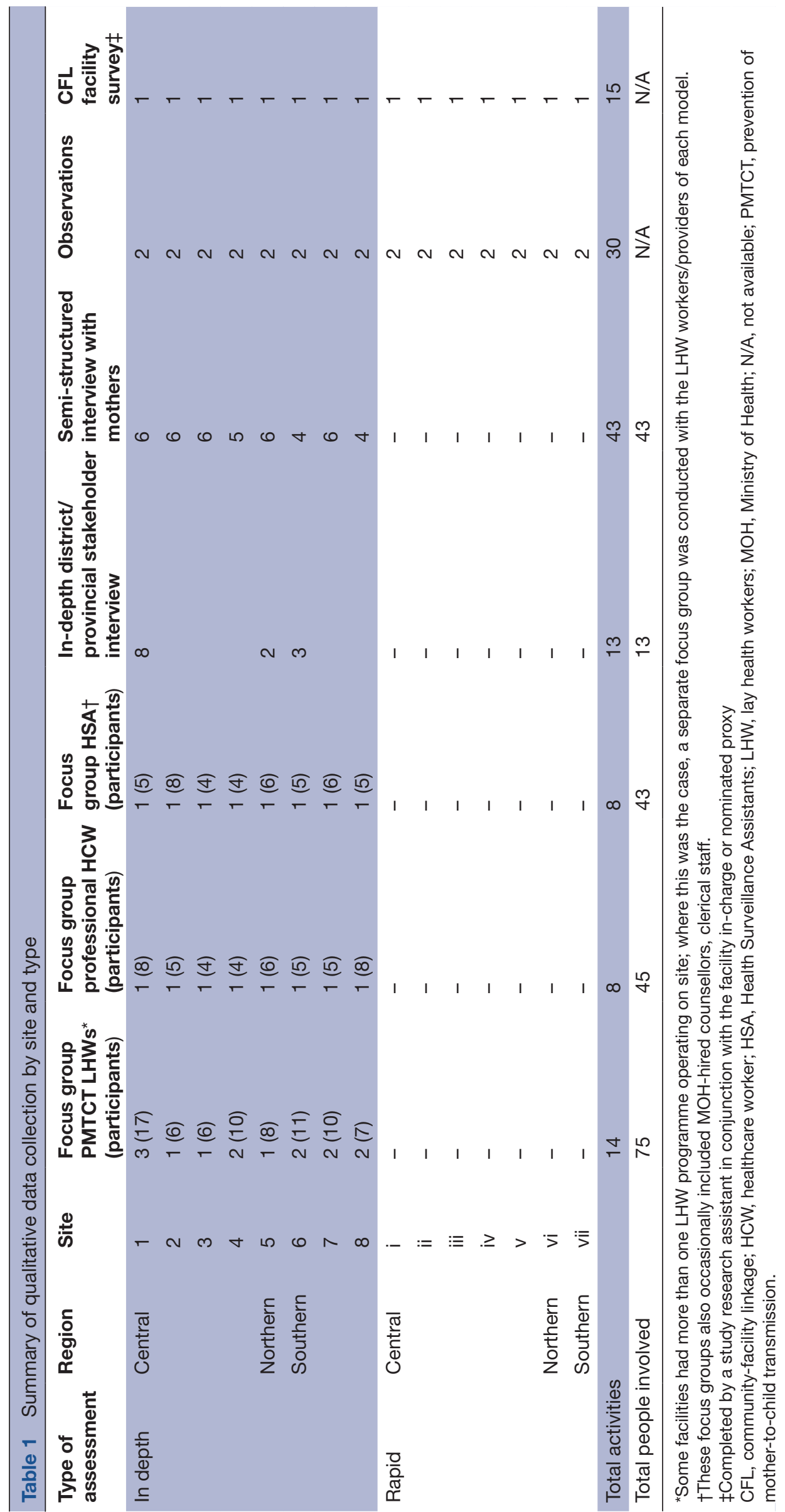


and tables and (f) interpretation by searching for relationships among themes or concepts identified and developing diagrams in order to map out relationships in the data. Two investigators (one additionally being the research manager), reviewed all qualitative data, independently identifying emergent themes and conferred to agree on final coding and findings.

\section{FINDINGS \\ Overview}

In the following, we first provide an overview of the approach and organisation of PMTCT LHWs for each of the three CFL models. In the subsequent section, drawing on multiple actors' accounts, we examine and distil key themes regarding the ways PMTCT LHWs are responding to ART uptake and retention barriers among pregnant and breastfeeding women in Malawi.

\section{Major features of three CFL models}

The major features of the three CFL models investigated are summarised in tables 2 and 3. Table 2 provides an overview of the three models and table 3 summarises types of organisation of PMTCT LHW in each model.

Although with differing emphasis, all three models used a combination of facility-based and community-based strategies. Common facility-based strategies included bolstering pre-test and post-test psychosocial counselling; navigation and accompaniment through the clinic and administrative support. Tingathe-CHW alone were also trained and responsible for dried blood spot testing of exposed infants. Common community-based strategies across the three models included tracing and follow-up of mother-infant pairs disengaged from care; homebased counselling and education visits and establishment of various types of peer-to-peer networks. Differences in

Table 2 Overview of three PMTCT lay health worker models operating in Malawi

\begin{tabular}{l}
\hline Expert Clients \\
\hline Management \\
Expert Clients are recruited and overseen \\
by several different non-government groups \\
(EGPAF, mothers2mothers) and at least one \\
District Health Office. In several districts, \\
Expert Clients are no longer supervised by \\
any organisation as project funds have run \\
out. These Expert Clients work independently, \\
relying on pre-existing relationships with \\
MOH clinic staff and the community.
\end{tabular}

\begin{abstract}
Recruitment and training
Expert Clients could be either men or women, who are living with HIV, are virally suppressed and open to others about their HIV status. They must be confident and willing to discuss their own experiences with HIV and ART in both group and one-on-one settings. There is no age requirement. Typically, Expert Clients were meant to have a Junior Certificate, although exceptions were made for highly articulate individuals, provided they could read and write. Expert Clients tended to be volunteers, sometimes receiving a monthly stipend. They usually received an initial training of about 2 weeks.
\end{abstract}

\section{Activities and relationships}

Expert Clients work in both the clinic and community setting. In the community, Expert Clients are mobile, and visit clients in their homes or other settings with no restrictions on the distances travelled. In the clinic,

Expert Clients are technically supposed to be based in both the ART and ANC departments. However, interview and observational data suggest that for various reasons (space, staff dynamics and relative time demand), Expert Clients are more usually based in ART, and visit ANC on a need-dependent basis.

Mentor Mothers

Mentors Mothers were recruited and overseen by the non-government organisation, mothers2mothers.

\section{Recruitment and training}

Mentor Mothers are all women, living with HIV who have been through the PMTCT cascade, so most of the mothers tend to be middle-aged. In order to be a Mentor Mother, a woman needed to disclose their status and be open to talking about living with HIV and living positively. All Mentor Mothers were required to have finished Form Four and be able to read and write. Mentor Mothers are recruited via advertisement and formal interviews by mothers2mothers staff. Prior to beginning their work they undergo a 2-week intensive training workshop covering the $\mathrm{MOH}$ HIV guidelines, and all $\mathrm{MOH}$ tools and mothers2mothers tools.

\section{Activities and relationships}

Mentor Mothers play roles at both facilities and in communities. In the facilities, Mentor Mothers are predominately in ANC. They welcome women to antenatal and help women to navigate the different queues for those coming to antenatal for the visit time. Facility-based Mentor Mothers interact with all women coming for their first antenatal visit regardless of their HIV test result, providing pretesting and post-testing support to all. While facilitybased mentor mothers conduct home visits within a $5 \mathrm{~km}$ radius, some sites also have community-based mentor mothers, who work predominately in the communities surrounding the health facilities. The two types of Mentor Mothers work together, have linkage registers and have monthly meetings to ensure clients from the community are linked to the facility and vice versa.

\section{Tingathe-CHW}

Management

Tingathe- $\mathrm{CHW}$ are recruited and overseen by the Baylor Tingathe programme. These $\mathrm{CHWs}$ are distinct from Malawi's cadre of government employed community-based public health agents called HSAs.

\section{Recruitment and training}

Tingathe-CHWs can be men or women, who may or may not be living with HIV. Although there is no formal age requirement, interviews and observations suggested the programme targets younger recruits due to the travel requirements (frequently on bike) of the job. Tingathe-CHWs must have a higher level of education compared with Expert Clients and Mentor Mothers, received 6 weeks initial training and ongoing quarterly updates. Tingathe- $\mathrm{CHWs}$ are required to live within the communities, so that they are 'embedded' and accessible community members. Tingathe-CHW are formal employees, and provided daily supportive supervision.

\section{Activities and relationships}

Tingathe-LHWs work in both the clinic and community setting. In the clinic, Tingathe$\mathrm{CHWs}$ tended to have their own (NGO-funded) offices. In their support work, they are based predominantly in the ART clinic, although were observed travelling around all clinical/hospital departments where the study observations took place. Reflecting their educational status, Tingathe-CHWs were observed to take on a number of higher-order coordination-style tasks in the facilities they worked in. In the community, Tingathe-CHW are highly mobile, visiting clients in their homes or other settings and they do not have any restrictions on the distances travelled. Most Tingathe- $\mathrm{CHW}$ active in the community had received a bicycle, improving their reach and efficiency. 


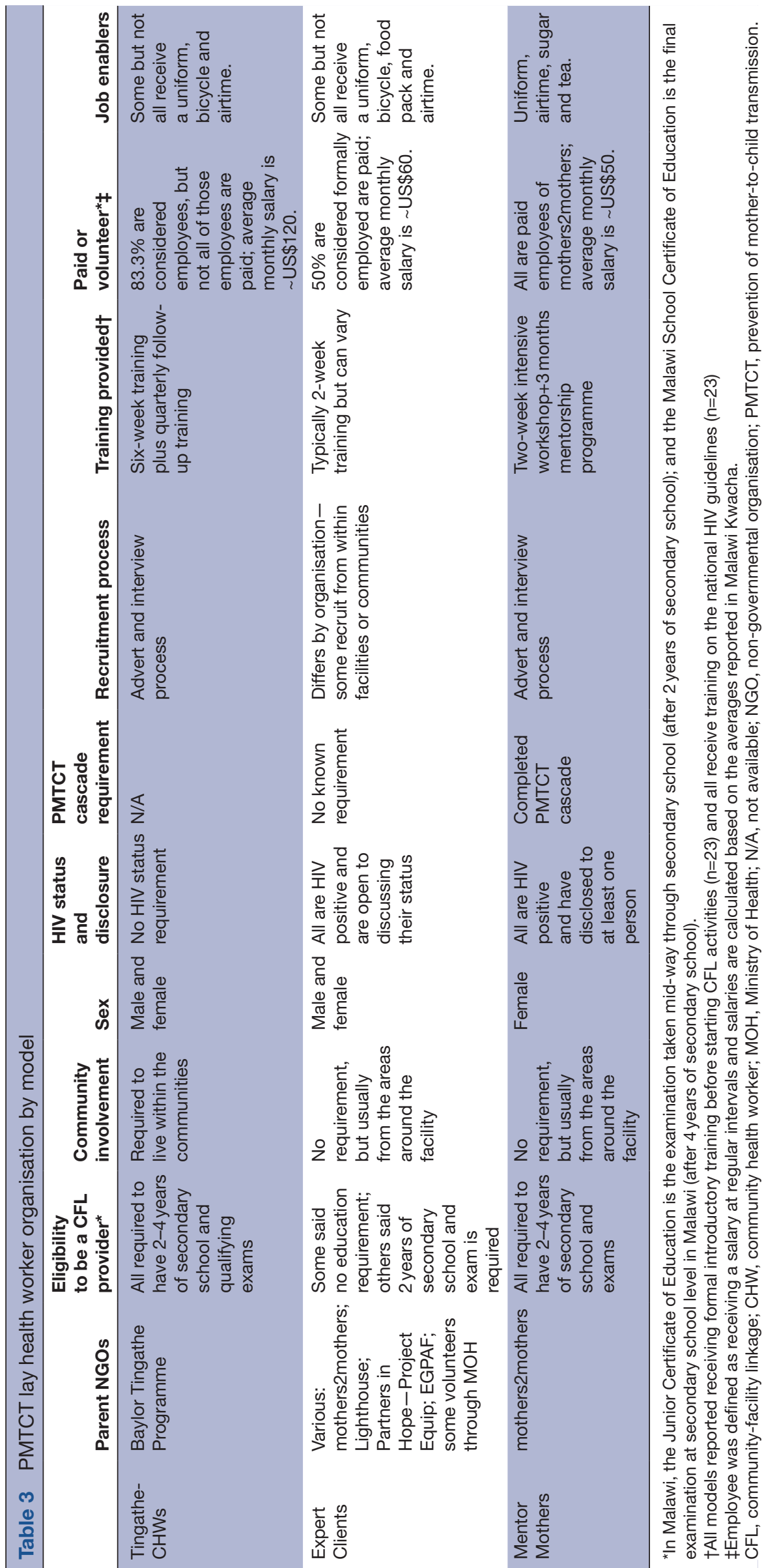


the degree of resourcing and mode of management and oversight by the various non-government partners were apparent, but closer examination of these goes beyond scope of this study and will be described elsewhere. Overall, we found a substantial degree of 'convergence' across the three cadres, with one exception. Expert Clients and Mentor Mothers programmes explicitly recruited from among individuals living with HIV, with participants noting these individuals had distinctive ability to connect with, and act as role models to, vulnerable clients living with HIV.

\section{How do PMTCT LHWs address barriers to uptake and retention?}

In this section, we organise findings to reflect four major themes regarding PMTCT LHWs contribution to addressing uptake and retention barriers, including: (i) addressing fear and uncertainty surrounding treatment; (ii) strengthening social connectedness and patient participation; (iii) enhancing frontline service function and (iv) improving CFL.

\section{Addressing fear, stigma and uncertainty}

PMTCT LHWs were described as, and observed to, carry out critical counselling and educational functions that responded to pregnant and breastfeeding women's fears in relation to HIV and treatment initiation. At all sites, health workers and clients described the opt-out policy of Option $\mathrm{B}+$ as producing uptake and retention challenges due often to the lack of 'readiness' among women. ${ }^{16}$

So they come here and they get tested and then they are told that: 'You have HIV and because of that you are support to start medication straight away'. For that person, these are two new things; first of all, she did not expect to have HIV and secondly she did not expect to start medication. So, within the time period, that person is not stable and what happens is like we are forcing her. She does not accept whole-heartedly. (MOH lay worker, site 4)

Fears of pregnant and breastfeeding women included those relating to spousal abandonment and resulting destitution, shame and community stigma. For others, concerns about HIV being a 'death sentence' and their capacity to be productive family and community members were prominent as in one mother's account below:

At the time when one has just found out their HIV status and start(-ed) treatment, (we) go through a stressful phase, thinking that life is over and (we) will be a sickly person.

(Mother 060, site 4)

At all sites, participants described PMTCT LHWs as helping to mitigate those fears through a range of strategies but primarily including formal and informal counselling, in both clinic and community settings.

Those people help to counsel us to the point where (we) are encouraged and at peace. (Mother 060, site 4)

Mother: They help us not to lose heart.

Interviewer: What should you not lose heart over?
Mother: That I should not be afraid in taking the medication. That there is no future for our lives. (Mother 021, site 4)

A number of mothers interviewed for the study emphasised the educational role played by PMTCT LHWs who allayed fears regarding the nature of the disease, and the processes of care in non-threatening and easy-tounderstand ways.

They are important because we would not know all this by ourselves. We are learning things from them teaching us. (And) they are very open with us compared to the nurses. We just go to the nurses to get the medication. But the (LHWs) explain to us. (Mother 086, site 5)

So when a person has just started receiving drugs, they don't know anything. They don't (know) how (treatment is) supposed to run. The (LHWs) help us understand. (Mother 012, site 2)

\section{Strengthening social connectedness and patient participation}

A second thematic finding was the role PMTCT LHWs played in enhancing social connectedness and patient participation in their own care. Many mothers in this study described their decisions about ART uptake and engagement as influenced by their immediate and broader social network. Spouses and family members were an important source of emotional and material support for some mothers, but for others, experiences or fear of stigma and discrimination prevented them from disclosing to their most important networks. Health workers and mothers described how PMTCT LHWs used counselling strategies to provide advice and support (often termed 'encouragement') to these relationships.

Yes, they (LHWs) are very important, because sometimes (we) are shy to come to the clinic in groups. But when they are conducting home visits, (LHWs) drive away shyness. (So that when) you come (to the clinic) and you see the group of your friends then you become free. To know you are not alone-we are so many! (Mother 035, site 2).

In addition, strategies to minimise those same mothers' social isolation were invoked. In the case of Expert Client and Mentor Mothers, role modelling of specific coping strategies and their positive outcomes was also described. Reflecting on the links between women's fears (above) and the potential for social isolation, several higher-level officials described the skill of the most effective PMTCT LHWs to evaluate clients' psychosocial state and use appropriate strategies based on the (material, symbolic, relational or service-related) challenges affecting a given client. Some professional health workers noted that this type of in-depth and deeply interpersonal work was not something that they themselves were equipped or had time to carry out.

Most of what they do, we cannot do! (Professional healthcare worker 1 , site 4 ) 


\section{Enhancing frontline services}

A third thematic finding was the role PMTCT LHWs played in strengthening service function in primary care facilities. At all sites, and among all stakeholder groups interviewed, PMTCT LHWs were recognised as helping clinic-based providers carry out their duties more efficiently, and effectively. Improved human resource capacity, reduced workload and the consequent ability to deliver more comprehensive services were all noted outcomes of PMTCT LHW presence at the study sites:

Expert Clients and (MentorMothers) simplify our tasks as health workers $[\ldots]$ so it becomes easier for the clients and for us. (Professional healthcare worker 3, site 4)

They are a bridge to the ART, so if they were not available things would not be as effective. ( $\mathrm{MOH}$ lay worker 6 , site 7 )

Tasks taken on by PMTCT LHWs that eased the load of professional workers and improved the efficiency of service delivery included: carrying out clinic-based and home-based counselling, completing documentation in registers, collecting dried blot spot samples (for Tingathe-CHW only) and providing patient accompaniment and navigation between clinic departments. At some study sites, PMTCT LHWs assumed complete (or near complete) responsibility for these tasks.

In multiple sites, the patient follow-up and outreach activities conducted by PMTCT LHWs were noted to overlap with the official remit of Malawi's government employed community health cadre, HSAs. Yet in focus group discussions, HSAs and other frontline providers noted that in part due to other human resource shortages HSAs had become so 'clinic-bound' in their responsibilities, that their outreach and tracing role had fallen by the wayside. Rather than being perceived as a professional threat, therefore, the relationship between PMTCT LHWs and government-employed staff was generally described as a positive one, as characterised in this account:

It is not one man's work. It means that if I am in testing, the clinician should send me the (client) and when am done (...), I send them back to the clinician. So, for us to achieve, we are only achieving because there is oneness. Everyone has their limits and everyone knows that 'this is where I stop and from here, this (other) person goes'. So, to cut it short, at this facility, our relationship is very good.

(Tingathe-CHW 5, site 8)

\section{Community-facility linkage}

A final important theme was the way PMTCT LHWs promoted stronger links between their community and facilities, and through this, improved ART uptake and retention. Beyond simply absorbing the workload of overburdened clinical professionals or providing counselling, education and outreach, LHWs were described by various participants as having a demonstrable and positive effect on broader service responsiveness.

Although less tangible in nature, the significance of more responsive service delivery was stressed by many, given a prevailing context of poor-or at least impersonal-services. Mothers described this responsiveness citing examples of often simple, but material demonstrations of respect, often lacking in their experience of clinic services:

They are important because they greet you and serve you with priority (Mother 069 , site 4 )

Other health professionals emphasised the way PMTCT LHWs were 'links' or 'bridges' between themselves and their clients, and between the clinic and the community—carrying out work that extended, but just as importantly enhanced their services through interpretation (linguistic and procedural) and physical representation:

For example, I am a clinician, well trained. Maybe more (educated) than Mentor Mothers or Expert Clients. But maybe I am from a different district, different culture (and) they are closer to the patients because they are right there in the community and it is like they speak the same language. (Professional healthcare worker 2, site 4)

Us as health workers (..) our target is on the time. Depending on the amount of work that we have we may just decide to talk with (clients) for about five minutes and we are done (...) The Expert Clients, however, spend a lot of time with the person until they understand. (Professional healthcare worker 4 , site 7)

In some sites, PMTCT LHWs explained how they were able to help clinicians advocate for change, such as one Expert Client who requested clinical staff to harmonise a patient's ART and antenatal care visit dates:

We go and talk to the nurse or even doctors and suggest that 'This person will come twice in the same month, is it possible to help her so she can only come once?' (Expert Client 3, site 4)

The knowledge (a form of 'intelligence') that PMTCT LHWs brought to bear on the work of clinicbased providers was also recognised at the next level of the health system. Both District and CFL programme managers reflected on the improved understanding of patient needs by clinical providers and higher level planners, and the potentially transformational impact of such understanding on their own responses and decisions:

For a long time, our programming has been focusing on care at the facility level. So as long as the patient comes to the facility, you give him ARVs, you give them an appointment date: 'You should come in two or three months' that was all. (So you) see them in the next two months and all you say is: 'How have you been taking medications?' But there are a lot of things that have been happening in the background. And this programme has given us useful information about those issues (...) You are able to interact with them at household level and you see a lot of challenges. And when you are able to deal with those issues from the community where they stay, you realise that the success of HIV care becomes more (complicated) than just giving them the medications and then expecting them to see them again after two months. (Doing it) that way you may not be able to appreciate most of the challenges our patients go through. (PMTCT LHW Programme Manager 1). 
I would say in summary that there is that great rapport between patient and (PMTCT LHWs). They try to create that environment so that we (health professionals) can understand how (and) why is it that these people are falling out from the treatment. (District Official 2)

Many PMTCT LHWs acknowledged and expressed pride in this linking and bridging role, reflecting on how (if done well) it enabled them to build client and community trust that went beyond their PMTCT remit.

I am an Expert Client and a person that works at the facility. Most of the people in the community see us here at the facility and so there are those who approach us in the community to tell us of others (who) are very sick. They ask us to make time to visit these individuals (who) tell us their challenges, and we encourage them and assist them. [Expert Client 4, site 6]

\section{DISCUSSION}

As ART and PMTCT programmes mature globally, and treatment scale up continues to accelerate in the "treat all' era, the complexities of designing and delivering services to support pregnant and breastfeeding women living with HIV, and their children, to durably engage in care have become more evident. McNairy et a $\vec{p}^{33}$ note that suboptimal retention continues to threaten the achievements of PMTCT programming in many settings, stating that 'no partial credit' should be given for improvements in the upstream targets (eg, enrolment in treatment) when the complexities of ensuring effective engagement and retention for women and their infants over time remain unresolved. Improved understanding of whether and how interventions such as PMTCT LHWs are addressing known barriers to engagement and retention in the current 'treat all' era is therefore important. Findings from this study contribute to that knowledge base, by exploring how PMTCT LHWs operating under three prevailing models of non-government support in Malawi are directly and indirectly responding to such challenges.

Although all the PMTCT LHWs in this study were recruited and trained to address specific uptake and retention challenges in Malawi's national PMTCT programme, study participants highlighted their less tangible work to promote community-facility linkage as one of their most important functions. On the service side, frontline providers and district-level planners linked these efforts to improved understanding of clients by providers, and improved facility responsiveness and person-centredness. In part, such impact could be viewed as a 'positive externality' of the improved human resource capacity in the clinics-as discussed further below. Yet study participants were at pains to describe something more distinctive; a cadre whose bridging role- "I am an Expert Client and a person that works at the facility"-systems knowledge, and moral authority enabled them to move beyond basic service functions to promote greater accountability among frontline staff through improved recognition, engagement with and response to client's needs. ${ }^{26}$
On the client and community side, PMTCT LHWs were described as, and observed to be, builders of community trust in health services, operating in ways that transcended their tracing or follow-up role. PMTCT LHWs drew on relational-as well as technical-skills, to establish or strengthen relationships through conversations and visitation in non-threatening home and community environments. These relationships were leveraged to build trust when mothers (and others) returned to the facility, thereby promoting virtuous cycles of interaction.

Health systems and human resource for health literature well-document the potential of lay or community health workers to enhance CFL in the ways outlined above ${ }^{34-38}$ Indeed, over a decade ago in 2010, Schneider and Lehmann ${ }^{26}$ observed:

the emergence of lay workers in South Africa does offer opportunities for improved access and quality of care. Harnessing this potential requires recognising their role as integral to the formal health system and as more complex than a one-way delegation of tasks [...]. If broader roles are accepted, a more formalised lay health worker infrastructure may lay the ground for new negotiated orders with local health services and a strengthening of primary healthcare.

Notwithstanding the different models under which they worked, our findings demonstrated PMTCT LHWs in Malawi are engaged in such a 'negotiated order', seeking to strengthen primary healthcare on a day-to-day basis by scaffolding connections between the formal health services, and community and social contexts, even while conducting more programme-specific activities.

In HIV-specific literature, despite early adoption and dependency on LHWs in ART programmes across subSaharan Africa, ${ }^{26} 3940$ discussion and debate about their role has tended to focus on the safety, quality, access gains and technical feasibility of deploying LHWs for specific services. ${ }^{25}{ }^{26}$ Much less has been said about the social and systems impact of LHWs, or, 'their role and location between the formal health services and communities. ${ }^{26}$ This potentially reflects the disciplinary focus in the HIV field on individually oriented and programme-specific interventions. But for countries with a high-burden of HIV and in an era of declining external funding, ART and PMTCT programmes are increasingly grappling with the imperative to integrate at least some functions of ART and primary healthcare service. In doing so, they face the long-standing conundrum ${ }^{25} 41$ of how to support ART uptake and retention outcomes within a broader health service environment that may not be resourced, or oriented to provide targeted support. Since the capacity to strengthen patient-centred care and responsiveness constitutes a core component of this struggle, the role of cadres such as Malawi's PMTCT LHWs in such a context takes on renewed significance.

Supporting existing evidence demonstrating the targeted role PMTCT LHWs can play in strengthening ART uptake and retention, ${ }^{18} 28$ PMTCT LHWs in all 
three models in this study were described as helping allay clients' fears through psycho-social counselling support and role modelling, as well as health education to improve understanding of HIV and services options, including rapid initiation of lifelong treatment. Our findings also demonstrated how the PMTCT LHWs addressed social barriers to uptake and retention, by using role modelling, (confidential) home visitation and group based counselling or support groups that help women build alternative networks. These findings are intuitive, given the growing body of research from Malawi and elsewhere ${ }^{43}$ documenting the multiple sociocultural and gender-based barriers to uptake and retention in care 30314445 including prevalent concerns about spousal abandonment or community rejection. ${ }^{15} 1746$ Although the focus in this study was PMTCT LHWs' role in promoting uptake and retention from a systems perspective, rather than womens' readiness to start treatment per se, our findings align well with McLean's framework, which identifies women's previous knowledge of HIV status, their relationships with healthcare workers, relationships with partners and roles/responsibilities as a mother, as key factors influencing treatment choices. ${ }^{16}$

A final important, if instrumental, contribution of PMTCT LHWs to improved PMTCT and ART uptake and retention identified in this study, was their bolstering of frontline human resource capacity of primary care clinics. Malawi has long experienced chronic health worker shortages and empirical studies have demonstrated the additional health system pressures that were created by the scale up of Option B+. Phiri et $a t^{47}$ describe 'severe pressure' on Malawi's health workers due to increased patient loads associated with Option B+ and reduced ability to deliver quality of care. Workload has been directly (although not exclusively) linked to provider disrespect and abuse of clients, with a substantial body of literature documenting the negative impact of disrespect and abuse in health services generally ${ }^{48} 49$ and maternal healthcare in particular. ${ }^{50-53}$ In a health system with recognised human resource shortages $^{54}$ and chronically overworked government employed healthcare providers, ${ }^{55}$ the sometimes poor quality of services was acknowledged by many in this study. We found the presence of PMTCT LHWs-irrespective of which model-was universally welcomed by governmentemployed health workers who described a reduction in workload stress, improved ability to deliver quality care and overall improvements in workplace morale related to basic improvements in human resource capacity.

\section{Strengths and limitations}

A strength of the study was the rich data set, drawing on multiple types of stakeholders from settings across Malawi. As it was nested within a broader study that sought to evaluate the programmatic impact of LHW models, there were some limitations on the design and scope of the qualitative component. We acknowledge the risk of social desirability bias, particularly in interviews with women enrolled in PMTCT and among PMTCT LHWs themselves. We sought to minimise the risk of such bias through careful training of a core set of four qualitative research assistants who conducted all interviews for the study's duration. Although study procedures were designed to facilitate participant comfort and trust and all due care was taken during informed consent processes, research assistants reported interviews with a number of women enrolled in PMTCT to be difficult, with some accounts lacking the desired depth. This was potentially due to underlying concerns about study purpose.

\section{CONCLUSION}

Drawing on client, health worker and policy makers' accounts, this study explores different actors perceptions of the way PMTCT LHWs are responding to barriers to ART uptake and retention barriers in Malawi. Study findings show that in the process of responding to client fears, strengthening social connectedness and improving facility function, PMTCT LHWs are directly addressing known individual, community and health service factors impacting uptake and retention in care. Analysis further demonstrates PMTCT LHWs are addressing uptake and retention barriers through less targeted but vitally important community-facility linkage functions that promote responsive and person-centred services. This analysis contributes to a burgeoning body of work demonstrating the hidden complexities of: i) achieving global targets such as UNAIDS' 95-95-95, in the context of highly resource-constrained heath systems, and ii) the importance of health workforce and service design that enables providers to address often overlooked social, cultural and health system factors affecting client access to, and engagement with, PMTCT and ART services. Further work to understand the governance and sustainability of these project-funded non-government administered models is now urgently required.

Twitter Stephanie M Topp @globalstopp and Godfrey Banda @Godfrey Banda

Acknowledgements The authors would like to thank the Malawian Ministry of Health, the three LHW programmes and all respondents for their time and generosity in participating in this study.

Contributors ST contributed to study design, provided oversight of data collection, led analysis and wrote the first draft of the manuscript. NC supervised data collection, contributed to analysis and provided critical edits to the manuscript. JS, LK and GB collected the data, contributed to analysis and provided critical edits. $\mathrm{MH}$ contributed to study design, provided overal study oversight, contributed to analysis and made critical edits to the manuscript.

Funding This work was supported by Project SOAR (Cooperative agreement AIDOAA-A-14-00060), made possible by the generous support of the American people through the United States President's Emergency Plan for AIDS Relief (PEPFAR) and United States Agency for International Development (USAID). MEH was also supported through the Fogarty International Centre at the National Institutes of Health (K01 TW010272). SMT is currently supported through a National Health and Medical Research Council (NHMRC) Investigator Grant (GNT1173004).

Disclaimer The contents of this paper are the sole responsibility of the authors and do not necessarily reflect the views of PEPFAR, USAID or the United States Government. The funders had no role in study design, data collection and analysis, decision to publish or preparation of the manuscript.

Competing interests None declared. 
Patient consent for publication Not required.

Ethics approval Ethical Approval was provided by the Malawi National Health Sciences Research Committee (\#17/05/1812), the Institutional Review Board of the University of North Carolina at Chapel Hill (\#17-1114) and James Cook University's Human Research Ethics Committee (\#1812).

Provenance and peer review Not commissioned; externally peer reviewed.

Data availability statement Some data are available on request. Respect for participant anonymity and consent which provided permission for use of data for this project only, mean qualitative data will not be available. De-identified quantitative survey data may be provided on request.

Open access This is an open access article distributed in accordance with the Creative Commons Attribution Non Commercial (CC BY-NC 4.0) license, which permits others to distribute, remix, adapt, build upon this work non-commercially, and license their derivative works on different terms, provided the original work is properly cited, appropriate credit is given, any changes made indicated, and the use is non-commercial. See: http://creativecommons.org/licenses/by-nc/4.0/.

ORCID iD

Stephanie M Topp http://orcid.org/0000-0002-3448-7983

\section{REFERENCES}

1 World Health Organization. Programmatic update: use of antiretroviral drugs for treating pregnant women and preventing HIV infection in infants. Geneva, 2012.

2 Hirnschall G, Harries AD, Easterbrook PJ, et al. The next generation of the world Health organization's global antiretroviral guidance. $J$ Int AIDS Soc 2013;16:18757.

3 Centers for Disease Control and Prevention (CDC). Impact of an innovative approach to prevent mother-to-child transmission of HIV-Malawi, July 2011-September 2012. MMWR Morb Mortal Wkly Rep 2013;62:148-51.

4 Kalua T, Tippett Barr BA, van Oosterhout JJ, et al. Lessons Learned From Option B+ in the Evolution Toward "Test and Start" From Malawi, Cameroon, and the United Republic of Tanzania. J Acquir Immune Defic Syndr 2017;75(Suppl 1):S43-50.

5 Tenthani L, Haas AD, Tweya $\mathrm{H}$, et al. Retention in care under universal antiretroviral therapy for HIV-infected pregnant and breastfeeding women ('Option B+') in Malawi. AIDS 2014;28:589-98.

$6 \mathrm{Kim} \mathrm{MH}$, Ahmed S, Hosseinipour MC, et al. Implementation and operational research: the impact of option $\mathrm{B}+$ on the antenatal PMTCT cascade in Lilongwe, Malawi. J Acquir Immune Defic Syndr 2015;68:e77-83.

7 Ministry of Health. Integrated HIV program report, January March 2016. Government of Malawi, 2016.

8 Knettel BA, Cichowitz C, Ngocho JS, et al. Retention in HIV care during pregnancy and the postpartum period in the option B+ era: systematic review and meta-analysis of studies in Africa. $J$ Acquir Immune Defic Syndr 2018;77:427-38.

9 Seeley J, Bond V, Yang B, et al. Understanding the time needed to link to care and start art in seven HPTN 071 (PopART) study communities in Zambia and South Africa. AIDS Behav 2019;23:929-46.

10 Hayes R, Floyd S, Schaap A, et al. A universal testing and treatment intervention to improve HIV control: one-year results from intervention communities in Zambia in the HPTN 071 (PopART) cluster-randomised trial. PLOS Med 2017;14:e1002292.

11 Iwuji CC, Orne-Gliemann J, Larmarange J, et al. Universal test and treat and the HIV epidemic in rural South Africa: a phase 4 , open-label, community cluster randomised trial. Lancet HIV 2018:5:e116-25.

12 Iwuji CC, Orne-Gliemann J, Larmarange J, et al. Uptake of homebased HIV testing, linkage to care, and community attitudes about art in rural KwaZulu-Natal, South Africa: descriptive results from the first phase of the ANRS 12249 TASP cluster-randomised trial. PLOS Med 2016;13:e1002107.

13 Reda AA, Biadgilign S. Determinants of adherence to antiretroviral therapy among HIV-infected patients in Africa. AIDS Res Treat 2012;2012:574656.

14 Simoni JM, Amico KR, Pearson CR, et al. Strategies for promoting adherence to antiretroviral therapy: a review of the literature. Curr Infect Dis Rep 2008;10:515-21.

$15 \mathrm{Ma}$, Tso LS, Rich ZC, et al. Barriers and facilitators of interventions for improving antiretroviral therapy adherence: a systematic review of global qualitative evidence. J Int AIDS Soc 2016;19:21166.
16 McLean E, Renju J, Wamoyi J, et al. 'I wanted to safeguard the baby': a qualitative study to understand the experiences of Option $\mathrm{B}+$ for pregnant women and the potential implications for 'testand-treat' in four sub-Saharan African settings. Sex Transm Infect 2017;93:e052972.

17 Flax VL, Yourkavitch J, Okello ES, et al. "If my husband leaves me, I will go home and suffer, so better cling to him and hide this thing": The influence of gender on Option B+ prevention of mother-tochild transmission participation in Malawi and Uganda. PLoS One 2017:12:e0178298.

18 Vrazo AC, Sullivan D, Ryan Phelps B. Eliminating mother-to-child transmission of HIV by 2030: 5 strategies to ensure continued progress. Glob Health Sci Pract 2018;6:249-56.

19 Wilkinson L, Grimsrud A, Cassidy T, et al. A cluster randomized controlled trial of extending ART refill intervals to six-monthly for anti-retroviral adherence clubs. BMC Infect Dis 2019;19:674.

20 Rasschaert F, Decroo T, Remartinez D, et al. Adapting a communitybased ART delivery model to the patients' needs: a mixed methods research in Tete, Mozambique. BMC Public Health 2014;14:364.

21 Khabala KB, Edwards JK, Baruani B, et al. Medication adherence clubs: a potential solution to managing large numbers of stable patients with multiple chronic diseases in informal settlements. Trop Med Int Health 2015;20:1265-70.

22 Celletti F, Wright A, Palen J, et al. Can the deployment of community health workers for the delivery of HIV services represent an effective and sustainable response to health workforce shortages? Results of a multicountry study. AIDS 2010;24(Suppl 1):S45-57.

23 Samb B, Celletti F, Holloway J, et al. Rapid expansion of the health workforce in response to the HIV epidemic. N Engl J Med 2007;357:2510-4.

24 Ivers LC, Jerome J-G, Cullen KA, et al. Task-shifting in HIV care: a case study of nurse-centered community-based care in rural Haiti. PLoS One 2011;6:e19276.

25 Hermann K, Van Damme W, Pariyo GW, et al. Community health workers for ART in sub-Saharan Africa: learning from experience-capitalizing on new opportunities. Hum Resour Health 2009;7:31.

26 Schneider H, Lehmann U. Lay health workers and HIV programmes: implications for health systems. AIDS Care 2010;22(Suppl 1):60-7.

27 Shroufi A, Mafara E, Saint-Sauveur JF, et al. Mother to mother (M2M) peer support for women in prevention of mother to child transmission (PMTCT) programmes: a qualitative study. PLoS One 2013;8:e64717.

28 Vrazo AC, Firth J, Amzel A, et al. Interventions to significantly improve service uptake and retention of HIV-positive pregnant women and HIV-exposed infants along the prevention of mother-tochild transmission continuum of care: systematic review. Trop Med Int Health 2018;23:136-48.

29 Ackerman L. Community-Facility linkages to support the scale-up of lifelong treatment for pregnant and breastfeeding women living with HIV: a conceptual framework, compendium of promising practices and key operational considerations. Geneva: UNICEF, 2015.

30 Carbone NB, Njala J, Jackson DJ, et al. "I would love if there was a young woman to encourage us, to ease our anxiety which we would have if we were alone": Adapting the Mothers2Mothers Mentor Mother Model for adolescent mothers living with HIV in Malawi. PLoS One 2019;14:e0217693.

31 Cataldo F, Sam-Agudu NA, Phiri S, et al. The roles of expert mothers engaged in prevention of mother-to-child transmission (PMTCT) programs: a commentary on the INSPIRE studies in Malawi, Nigeria, and Zimbabwe. J Acquir Immune Defic Syndr 2017;75(Suppl 2):S224-32.

32 Pope C, Mays N. Reaching the parts other methods cannot reach: an introduction to qualitative methods in health and health services research. BMJ 1995;311:42-5.

33 McNairy ML, Teasdale CA, El-Sadr WM, et al. Mother and child both matter: reconceptualizing the prevention of mother-to-child transmission care continuum. Curr Opin HIV AIDS 2015;10:403-10.

34 Friedman I. Community health workers and community care-givers: Towards a model of unified practice. In: ljumba P, Barron P, eds. South African health review. Durban: Health Systems Trust, 2005.

35 Lehmann U, Sanders D. Community health workers: what do we know about them? The state of the evidence on programmes, activities, costs and impact on health workers. Evidence and information for policy. Geneva: World Health Organization, 2007.

36 Standing $\mathrm{H}$, Chowdhury AMR. Producing effective knowledge agents in a pluralistic environment: what future for community health workers? Soc Sci Med 2008;66:2096-107.

37 Walt G. Community health workers in national programmes: just another pair of hands? Philadelphia: Open University Press, 1990

38 Glenton C, Colvin CJ, Carlsen B, et al. Barriers and facilitators to the implementation of lay health worker programmes to improve 
access to maternal and child health: qualitative evidence synthesis. Cochrane Database Syst Rev 2013;10:CD010414.

39 Joseph JK, Rigodon J, Cancedda C, et al. Lay health workers and HIV care in rural Lesotho: a report from the field. AIDS Patient Care STDS 2012;26:141-7.

40 Puchalski Ritchie LM, van Lettow M, Barnsley J, et al. Lay health workers experience of a tailored knowledge translation intervention to improve job skills and knowledge: a qualitative study in Zomba district Malawi. BMC Med Educ 2016;16:54

41 Schneider H, Coetzee D. Strengthening the health system and ensuring equity in the widescale implementation of an antiretroviral therapy programme in South Africa. S Afr Med J 2003;93:772-3.

42 Schmitz K, Basera TJ, Egbujie B, et al. Impact of lay health worker programmes on the health outcomes of mother-child pairs of HIV exposed children in Africa: a scoping review. PLoS One 2019;14:e0211439.

43 Kiwanuka G, Kiwanuka N, Muneza F, et al. Retention of HIV infected pregnant and breastfeeding women on option $\mathrm{B}+$ in Gomba district, Uganda: a retrospective cohort study. BMC Infect Dis 2018;18:533.

44 Haas AD, Msukwa MT, Egger M, et al. Adherence to antiretroviral therapy during and after pregnancy: cohort study on women receiving care in Malawi's option B+ program. Clin Infect Dis 2016;63:ciw500:1227-35.

45 Rao D, Chen WT, Pearson CR, et al. Social support mediates the relationship between HIV stigma and depression/quality of life among people living with HIV in Beijing, China. Int J STD AIDS 2012;23:481-4.

46 Fatti G, Mothibi E, Shaikh N, et al. Improved long-term antiretroviral treatment outcomes amongst patients receiving community-based adherence support in South Africa. AIDS Care 2016;28:1365-72.
47 Phiri N, Tal K, Somerville C, et al. "I do all I can but I still fail them": Health system barriers to providing Option $\mathrm{B}+$ to pregnant and lactating women in Malawi. PLoS One 2019;14:e0222138.

48 Miedema B, Easley J, Fortin P, et al. Disrespect, harassment, and abuse: all in a day's work for family physicians. Can Fam Physician 2009;55:279-85.

49 Ferreira M, Lindgren P. Elder abuse and neglect in South Africa: a case of marginalization, disrespect, exploitation and violence. J Elder Abuse Negl 2008;20:91-107.

50 Galle A, Manaharlal H, Cumbane E, et al. Disrespect and abuse during facility-based childbirth in southern Mozambique: a crosssectional study. BMC Pregnancy Childbirth 2019;19:369.

51 Sen G, Reddy B, lyer A, et al. Addressing disrespect and abuse during childbirth in facilities. Reprod Health Matters 2018;26:1-5.

52 Bhattacharya S, Sundari Ravindran TK. Silent voices: institutional disrespect and abuse during delivery among women of Varanasi district, Northern India. BMC Pregnancy Childbirth 2018;18:338.

53 Freedman LP, Kruk ME. Disrespect and abuse of women in childbirth: challenging the global quality and accountability agendas. Lancet 2014;384:e42-4.

54 McCoy D, McPake B, Mwapasa V. The double burden of human resource and HIV crises: a case study of Malawi. Hum Resour Health 2008;6:16.

55 Smith S, Deveridge A, Berman J, et al. Task-shifting and prioritization: a situational analysis examining the role and experiences of community health workers in Malawi. Hum Resour Health 2014;12:24

56 Kok MC, Namakhoma I, Nyirenda L, et al. Health surveillance assistants as intermediates between the community and health sector in Malawi: exploring how relationships influence performance. BMC Health Serv Res 2016;16:164. 